\title{
The Epidemiological, Clinical, Biological and Morphological Characteristics of Primitive Liver Cancers in Bangui
}

\author{
Serges Magloire Camengo Police ${ }^{1}$, Georges Service ${ }^{2}$, Nathalie Philomène Boua-Akelelo1, \\ Diane N'guilé1, Benoît Elowa1, Timothée Mobima3 ${ }^{3}$ Francky Kouandogui Bangué4, \\ Eveline Mofini', Yangba Kalebanga Armelo Thibaut ${ }^{1}$, Bessanguem Bernard1', Boniface Koffi ${ }^{5}$
}

\footnotetext{
${ }^{1}$ Department of Hepatogastroenterology and Internal Medicine of “Amitié Sino-Centrafraine” University Hospital Center, Bangui, Central African Republic

${ }^{2}$ Department of Internal Medicine "Maman Elisabeth Domitien” University Hospital Center, Bimbo, Central African Republic

${ }^{3}$ Department of Radioloy and Medical Imaging of "Amitié Sino-Centrafraine” University Hospital Center, Bangui, Central African Republic

${ }^{4}$ Department of Radioloy and Medical Imaging of “Maman Elisabeth Domitien” University Hospital Center, Bimbo, Central African Republic

${ }^{5}$ Department Pathological Anatomy National Laboratory of Clinical Body and Public Health, Bangui, Central African Republic Email: *camengop@netcourrier.com
}

\begin{abstract}
How to cite this paper: Police, S.M.C., Service, G., Boua-Akelelo, N.P., N'guilé, D., Elowa, B., Mobima, T., Bangué, F.K., Mofini, E., Thibaut, Y.K.A., Bernard, B. and Koffi, B. (2020) The Epidemiological, Clinical, Biological and Morphological Characteristics of Primitive Liver Cancers in Bangui. Open Journal of Gastroenterology, 10, 97-105.
\end{abstract}

https://doi.org/10.4236/ojgas.2020.104010

Received: March 4, 2020

Accepted: April 17, 2020

Published: April 20, 2020

Copyright $\odot 2020$ by author(s) and Scientific Research Publishing Inc. This work is licensed under the Creative Commons Attribution International License (CC BY 4.0).

http://creativecommons.org/licenses/by/4.0/

(c) (i) Open Access

\begin{abstract}
Objective: To describe the epidemiological, clinical, biological and morphological aspects of primary liver cancer (PLC). Patients and Methods: We conducted a 38-month cross-sectional study in the Department of hepatogastroenterology and Internal Medicine "Amitié Sino-Centrafraine" University Hospital Center in Bangui. Included in the study were all patients with a diagnosis of PLC. The PLC's diagnostic arguments were the large tumor liver associated or not with the elevation of alpha-fetoprotein, the heteronodular liver hypervascularized on abdominal ultrasound. Data analysis was done using Epi Info 3.5.1 software. Results: We collected 115 cases of CPF among 2410 hospitalized patients (4.7\%). There were 86 men and 29 women (sex ratio: 2.9). The average age was 50 years old. The main risk factors were alcohol consumption (72.2\%) and chronic hepatitis B infection (67.4\%). Frequent clinical signs were pain in the right hypochondrium and/or epigastric (93.86\%), large tumor liver under examination (91.3\%), weight loss $(74.78 \%)$. The serum alpha-fetoprotein concentration was $\geq 400 \mathrm{ng} / \mathrm{ml}$ in $73 \%$ of the cases. The abdominal ultrasound found a heteronodular liver in all patients. The nodules were multiple hyperechoic in $66.1 \%$ of the cases. According to the Child-Pugh classification, the patients were classified as B (49.5\%) and C
\end{abstract}


(33.9\%). The Okuda Classification ranked patients at stage 1 in $16.5 \%$ cases, stage 2 in $52.1 \%$ cases and stage 3 in $31.3 \%$ cases. According to the BCLC classification, $5.2 \%$ of patients were in stage A, $12.2 \%$ in stage $\mathrm{B}, 52.2$ in stage $\mathrm{C}$ and $30.4 \%$ in stage D. Death was recorded during hospitalization in 89 cases (77.4\%). Conclusion: $\mathrm{CPF}$ is a frequent and serious pathology in Bangui. Its diagnosis is often late, preventing curative treatment. The main causes are alcohol consumption and the hepatitis $\mathrm{B}$ virus. The population should be educated to reduce the incidence of this disease.

\section{Keywords}

Primary Liver Cancer, Epidemiology, Clinical, Morphology, Bangui

\section{Introduction}

Primary liver cancer (PLC) is a public health problem worldwide. It is the sixth cancer in the world and the fourth leading cause of neoplastic death after cancer of the lung, colon rectum and stomach [1]. Hepatocellular carcinoma (HCC) is the most common histological form. In developed countries, HCC is usually discovered early, as part of the follow-up to cirrhosis [2]. In black Africa, HCC is still a pathology of late discovery, at the massive tumor stage, signifying the severity of the disease [3]. In Congo, the HCC represents the first malignant disease and the fourth cause of hospitalizations for liver diseases [4]. In sub-Saharan Africa, hepatocellular carcinoma is common in young people, most often male [5]. In the Central African Republic, hepatocellular carcinoma accounts for $20.2 \%$ of complications from cirrhosis [6]. The most common aetiologies of HCC are hepatitis B virus (HBV), alcohol and hepatitis C virus (HCV) [1]. In East Asia and sub-Saharan Africa, the most dominant risk factor is chronic infection with the HBV [7]. While in Egypt, it is the hepatitis C virus which is the first cause of HCC [8]. The serious nature of HCC leads us to study its epidemiological, clinical, biological and morphological characteristics in a country with limited resources, in order to contribute to the improvement of its management.

\section{Patients and Methods}

We conducted a 38-month cross-sectional study from April 17, 2010 to June 16, 2013 in the Department of hepatogastroenterology and Internal Medicine "Amitié Sino-Centrafraine" University Hospital Center of Bangui. The study included consenting patients of both gender who were diagnosed with primary liver cancer (PLC). The PLC's diagnostic arguments were clinical (irregular, sensitive or painful hard hepatomegaly with crenellated lower edge; deterioration in general condition); biological (high alpha-fetoprotein $\geq 400 \mathrm{ng} / \mathrm{ml}$, but normal AFP did not rule out the diagnosis); ultrasound (heteronodular hypervascular liver in doppler mode). The abdominal ultrasound was performed by two operators (a hepato-gastroenterologist and a radiologist). Our sample was of convenience 
covering all cases diagnosed during the study period. Data collection was done using an individual direct administration survey form. Information was collected from patients, in the patient file, hospital records, abdominal ultrasound and upper digestive endoscopy registers. The variables studied were characteristics, socio-demographic, risk factors, clinical signs, biological characteristics, ultrasound signs, course and prognosis. Child-Pugh classification (using 1 to 3 points as side parameters: ascites, hepatic encephalopathy, bilirubinemia, prothrombin level, albuminemia) was used to assess the degree of hepatocellular insufficiency [9]. The Okuda classification [10] and the BCLC (Barcelona Clinic Liver Cancer) classification were used to assess the severity of HCC. Data entry and analysis use Epi info 3.5.1 software.

\section{Results}

During the study period, 2410 patients were admitted to the Service, including 115 for PLC (4.7\%). These were 86 men (74.8\%) and 29 women (25.2\%). The sex ratio was 2.96. The PLC ranks first among cancers in the service before head cancer of the pancreas 5 cases $(0.2 \%)$, stomach cancer 3 cases $(0.1 \%)$ and rectal cancer 1 case $(0.04 \%)$. The average age was $50 \pm 16$ years. Table 1 presents the distribution by sex and age group.

The antecedents found in our patients were the consumption of alcohol in 83 cases $(72.2 \%)$ with a daily average amount consumed of $71.8 \mathrm{~g} / \mathrm{l}$ (range: 20 and $360 \mathrm{~g} / \mathrm{d}$ ). The average duration of alcohol consumption was 21.6 years (range: 1 and 60 years). Tobacco consumption was found in 18 cases (15.6\%) with an average of 14.8 packs per year (extremes: 1 and 40 packs-year). The patients had known cirrhosis in 71 cases (61.7\%). The average duration of knowledge of cirrhosis is $1.8 \pm 5$ months. The other antecedents found were jaundice in 39 cases (33.9\%), chronic viral hepatitis B in 19 cases (16.5\%), chronic viral hepatitis $C$ in 5 cases $(4.3 \%)$ and blood transfusion in 8 cases (6.9\%). For patients with a history of hepatitis $\mathrm{B}$, the mean duration of knowledge of babywearing was 12.3 years (range: 1 and 40 years). The clinical signs are presented in Table 2 .

Alpha-fetoprotein (AFP) was performed in all patients. Its value was $\geq 400$ $\mathrm{ng} / \mathrm{ml}$ in 96 patients (83.5\%). Prothrombin rate was low, less than $70 \%$ in 95 patients (82.6\%). Total bilirubinemia was greater than $91 \mu \mathrm{mol} / \mathrm{l}$ in 96 patients (83.5\%). Serum protein electrophoresis had shown hypoalbuminemia in 85 cases

Table 1. Distribution of patients by sex and age group.

\begin{tabular}{cccccccc}
\hline \multirow{2}{*}{ Age range } & \multicolumn{3}{c}{ Sex } & \multicolumn{3}{c}{ Total } \\
\cline { 2 - 6 } & \multicolumn{2}{c}{ Feminine } & \multicolumn{2}{c}{ Male } & \multicolumn{2}{c}{ Effective } & $\%$ \\
\hline Age (year) & Effective & $\%$ & Effective & $\%$ & $(39.53)$ & 51 & $(44.35)$ \\
\hline $19-35$ & 17 & $(58.62)$ & 34 & 39 & $(45.35)$ & 50 & $(43.48)$ \\
$36-52$ & 11 & $(37.93)$ & $(3.45)$ & 13 & $(15.12)$ & 14 & $(12.17)$ \\
$\geq 53$ & 1 & $(100)$ & 86 & $(100)$ & 115 & $(100)$ \\
Total & 29 & & & & & &
\end{tabular}


(73.9\%). The beta-gamma block was observed in 57 cases (49.6\%). Thrombocytopenia was observed in 91 patients (79.1\%). It was less than $100,000 / \mathrm{mm}^{3}$ in 63 patients (54.8\%). The mean and extreme values of alpha-fetoprotein, prothrombin rate, bilirubinemia, albuminemia and platelets are presented in Table 3.

HBsAg was sought in all patients. It was positive in 78 cases $(67.8 \%)$, of which, 8 patients (6.9\%) had anti-HDV Antibodies. Anti HCV antibodies were positive in 13 patients (11.3\%). The viral load of HCV and HDV was not achieved. HIV serology was positive in 6 patients (5.2\%), who were also infected with HBV. The abdominal ultrasound showed hepatic nodules in all cases. It was a single nodule in 20 cases $(17.4 \%)$ and multiple nodules in 95 cases $(82.6 \%)$. The size of the single nodules varied from 25 to $80 \mathrm{~mm}$ with an average of $57 \mathrm{~mm}$ in diameter. The size of the multiple nodules varied from 60 to $130 \mathrm{~mm}$ with an average of $81 \mathrm{~mm}$ in diameter. The nodules were hyperechoic in 76 cases (66.1\%), hypoechoic in 29 cases $(25.2 \%)$, isoechoic in 10 cases $(8.7 \%)$. The abdominal ultrasound revealed signs of portal hypertension (splenomegaly, dilation of the portal vein and splenic vein) in 96 cases (83.5\%). Portal thrombosis was found in 26 cases

Table 2. Clinical signs.

\begin{tabular}{ccc}
\hline Signs & Effective $(\mathbf{n}=115)$ & $\%$ \\
\hline Functional signs & 107 & \\
Right hypochondrium and/or epigastric pain & 32 & 93.9 \\
Impaired consciousness & 12 & 27.8 \\
Hematemesis and/or melena & & 10.4 \\
General signs & 43 & \\
Fever & 86 & 37.4 \\
Emaciation & 113 & 74.8 \\
Anorexia & 115 & 100 \\
Physical asthenia & & \\
Physical signs & 39 & 33.9 \\
Jaundice & 73 & 63.5 \\
Ascites & 70 & 60.9 \\
Collateral venous circulation & 105 & 91.3 \\
Tumoral hepatomegaly & 40 & 34.8 \\
Splenomegaly & 3 & 2.6 \\
\hline Left clavicular lymphadenopathy & &
\end{tabular}

Table 3. Average and extreme values of biological examinations.

\begin{tabular}{ccc}
\hline Biological tests & Average & Extremes \\
\hline AFP & $568 \mathrm{ng} / \mathrm{ml}$ & 16 et $235,840 \mathrm{ng} / \mathrm{ml}$ \\
Prothrombin rate & $57 \%$ & 17 and $100 \%$ \\
Bilirubin & $83 \mu \mathrm{mol} / \mathrm{l}$ & 6 and $432 \mu \mathrm{mol} / 1$ \\
Albuminemia & $26 \mathrm{~g} / \mathrm{l}$ & 18 and $39 \mathrm{~g} / \mathrm{l}$ \\
Platelets & $118,000 / \mathrm{mm}^{3}$ & 65,200 and $147,000 / \mathrm{mm}^{3}$
\end{tabular}


(22.6\%) and deep lymphadenopathy in 9 cases $(7.8 \%)$. Upper gastrointestinal endoscopy (UGE) was normal in 8 cases (6.9\%) and revealed esophageal varices $(\mathrm{EV})$ in 107 cases (93\%). These were stage $1 \mathrm{EV}$ in 12 cases (10.4\%), stage $2 \mathrm{EV}$ in 74 cases $(64.4 \%)$, stage $3 \mathrm{EV}$ in 21 cases (18.3\%). The associated endoscopic anomalies were mosaic gastropathy in 19 cases (16.5\%). The chest X-ray revealed "balloon release" images reflecting lung metastases in 4 cases (3.5\%), and pleural effusion in 6 cases (5.2\%). According to the Child-Pugh classification, the patients were in class A in 19 cases (16.5\%), class B in 57 cases (49.6\%), class $\mathrm{C}$ in 39 cases $(33.9 \%)$. The Okuda Classification showed stage 1 in 19 cases (16.5\%), stage 2 in 54 cases (47\%) and stage 3 in 42 cases (36.5\%). Table 4 shows the BCLC classification of the patients.

PLC had arisen from cirrhosis in 107 cases (93\%). Death was observed during hospitalization in 89 cases $(77.4 \%)$, of which 21 (23.6\%) died within 8 days of diagnosis, 54 (64\%) within 14 days of diagnosis and 11 (12.4\%) within 28 days. The mean survival time was 19 days (range: 2 and 75). Twenty-six patients (22.6\%) were released in a stationary state. They would probably have died at home. The mean survival time was 19 days with extremes ranging from 2 days to 75 days. $25 \%$ of patients died within 8 days of diagnosis, $50 \%$ within 14 days and $75 \%$ within 28 days.

\section{Discussion}

In our series, no patient was able to do a abdominal computed tomography (CT) because it was not available in the Central African Republic. Which could confirm the characteristics of hepatocellular carcinoma. The most suggestive abdominal CT sign of HCC is the existence of a hypervascularized nodule in the early arterial phase with late wash-out in the portal phase [11]. We also did not perform the hepatic biopsy puncture (PBH) for the histological analysis, taking into account the number of nodules, their bulky size, the deterioration of the general state, the significant elevation of the AFP. The characters of the liver associated or not with the elevation of the AFP and the characters ultrasound were strong arguments, which had allowed us to retain the diagnosis. The characters of the liver testify to the late stage at which the diagnosis of PLC is made in our environment. In this context, it is ethically difficult for us to make an invasive medical gesture that could not provide curative therapeutic possibilities, especially since the thrombocytopenia was less than $100,000 / \mathrm{mm}^{3}$ in 63 patients $(54.8 \%)$

Table 4. BCLC classification.

\begin{tabular}{cc}
\hline Stage & Effective (\%) \\
\hline Early stage (A) & $6(5.2)$ \\
Intermediate stage (B) & $14(12.2)$ \\
Advanced stage (C) & $60(52.2)$ \\
Terminal stage (D) & $35(30.4)$ \\
Total & $115(100)$ \\
\hline
\end{tabular}


and low prothrombin rate in $82.6 \%$ of patients. Some African authors have also demonstrated the contribution of abdominal ultrasound in the diagnosis of HCC [3]. The frequency of the PLC of $4.7 \%$ in our series is higher than that observed by the authors in Congo Brazzaville [4] and in Bukavu [12] which was $2.4 \%$. It is however lower than that reported by the authors in Togo which is 5.1\% [13]. Although these results are not comparable due to the difference in study duration, they nevertheless have the merit of showing that liver cancers represent a high proportion in digestive tumor pathology in sub-Saharan Africa. The predominance of men found in our series corroborates data from the African literature [3] [4] [5] [8] [12]-[18] and Western [19] [20]. The average age of our 50 -year-old patients is similar to that found in studies in sub-Saharan Africa, which varies between 39 and 50 years [3] [4] [5] [12] [13] [14] [15] [18]. In Algeria, the authors reported an average age of 62.35 years [17] and 66.4 years in France [21]. In Japan, the average age of patients with hepatocellular carcinoma is 58 years in men and 61.5 years in women [22]. It appears that PLC is common in young adults in sub-Saharan Africa. It would probably be linked on the one hand to life expectancy which is lower in sub-Saharan Africa than in the Maghreb and in the West and on the other hand, to the fact that Sub-Saharan Africa is located in an area of high prevalence of hepatitis B as evidenced by the first etiology of HCC in our study and in the studies of other authors [3]-[7] [11]-[22]. The diagnosis of PLC in Europe, in the patient at an advanced age is probably partly linked to the better management of cirrhosis which would delay the onset of HCC. The alcohol consumption reported by 83 patients (72.2\%) in our series had also been reported by other sub-Saharan authors [3] [4] [12] [13] [16] [17] as well as by Western and Asian authors [1] [2] [19] [21] [22]. However, alcohol is the number one cause of PLC in the West [1] [2] [21]. Increased alcohol consumption in Africa may also be a factor in the progression of liver disease in chronic HBV carriers, who did not know their HIV status. In our study, 93\% of patients had cirrhosis. These results corroborate the data in the literature, which asserts that HCC most often occurs on cirrhosis [4] [12] [14] [19] [20] [21] [22]. Pain in the right hypochondrium, a more common functional sign in our patients, has also been reported by other authors [17] [18] [21]. According to some authors, patients consulted for abdominal pain without specifying the site [3] [13]. In our context, the existence of abdominal pain in young adults should lead to the prescription of an abdominal ultrasound with emphasis on the liver echostructure, which would allow early detection. The large tumor liver observed in our patients in 91.3\% was also reported by other authors [3] [4] [13] [17] [18]. It explains the late stage at which the diagnosis of HCC is made in our communities. The delay in consultation is probably linked to the use of traditional medicine, self-medication, poverty. The value of alpha-fetoprotein was $\geq 400 \mathrm{ng} / \mathrm{ml}$ in $83.5 \%$ of the patients. This marker had been found at significant values by other African [3] [4] [13] [17] and European [21] authors. Abdominal ultrasound revealed hepatomegaly sits on multiple hypervascularized nodules in $82.6 \%$ of the cases in our study. In Burkina Faso [3], Brazzaville in Congo [4], Bukavu 
in the Democratic Republic of Congo [12], Lome in Togo [13] and Algeria [17], the authors had observed multiple hepatic nodules in respectively $67.2 \%$, $52 \%, 74.4 \%, 70.2 \%, 62 \%$. Multinodular or diffuse liver on abdominal ultrasound was also reported by the authors in Calvados in France in 50.8\% [21]. All this shows the advanced stage at which the diagnosis of PLC is made even in the wealthy countries. The difficulty in the progressive follow-up of our cirrhotic patients and the late discovery of PLC could explain the fact that the majority of our patients had large hyperechoic multiple tumors. The authors also reported that in Africa the liver is often multinodular [8]. The presence of tumor hepatomegaly associated with the hypervascularized nature of liver nodules on doppler ultrasound and the significant increase in alpha-fetoprotein are important parameters in countries without abdominal CT allowing them to accept the diagnosis of carcinoma hepatocellular. The alpha fetoprotein remains at least an alarm marker and even certain for the diagnosis of HCC when its value is $\geq 400$ $\mathrm{ng} / \mathrm{ml}$. According to the Child-Pugh classification, the patients were classified B and $\mathrm{C}$ in respectively $49.6 \%$ and $33.9 \%$ probably reflecting PLC occurring on liver from cirrhosis. The authors had reported that in Egypt $62 \%$ of patients were at stage C BCLC and 7\% at stage D, while in the other African countries 23\% were at stage $C$ and $72 \%$ at stage B st in the other African countries. Alosque $72 \%$ arrive at BCLC stage D and 7\% in Egypt [8]. According to the classification of Okuda and BCLC, our patients arrived late at an advanced and terminal stage, as some authors have also shown [17]. Death was observed in 89 patients $(77.4 \%)$ in our series. While some authors have reported a death rate of $40 \%$ in Lome in Togo [13], 80\% in Brazzaville in Congo [4], 5.6\% in Bukavu in the Democratic Republic of Congo. However, in Bukavu, $94.4 \%$ other patients had a steady state [12]. The average survival time after diagnosis was 19 days with extremes ranging from 2 days to 75 days. According to other authors [13], the death occurred within the first six months. In Brazzaville, Congo, $70 \%$ of the patients had died in the service [4]. For other authors, the median survival at 1 year is $78 \pm 12$ days. The poor survival in our series and in the other studies testifies to the seriousness of the HCC whose diagnosis is made late and does not allow curative treatment. Some patients in our series could have benefited from curative treatment, but for lack of technical platform and financial means, the latter saw their condition worse.

\section{Conclusion}

PLC is a frequent and serious condition of late discovery. It is a more common condition in young adult males. The main cause is chronic HBV infection and alcohol consumption. Signs suggestive are pain from hypochondre pain, deterioration of general condition, large tumor, elevated AFP, and large heteronodular liver on abdominal ultrasound. It therefore seems important to raise awareness of the risk factors for chronic liver disease. Cirrhotic patients should be monitored regularly to detect small curable small nodules early. 


\section{Conflicts of Interest}

The authors declare no conflicts of interest regarding the publication of this paper.

\section{References}

[1] Akinyemiju, T., Abera, S., Ahmed, M., et al. (2017) The Burden of Primary Liver Cancer and Underlying Etiologies from 1990 to 2015 at the Global, Regional, and National Level. JAMA Oncology, 3, 1683-1691. https://doi.org/10.1001/jamaoncol.2017.3055

[2] Nordenstedt, H., White, D.L. and El-Serag, H.B. (2010) The Changing Pattern of Epidemiology in Hepatocellular Carcinoma. Digestive Liver Disease, 42, S206-S214. https://doi.org/10.1016/S1590-8658(10)60507-5

[3] Nikiema, Z., Sawadogo, A., Kyelem, C.G., et al. (2010) Carcinomes hépatocellulaires en milieu africain burkinabè: Contribution de l'échographie à propos de 58 cas. The Pan African Medical Journal, 7, 10. https://doi.org/10.4314/pamj.v7i1.69116

[4] Ibara, J.R., Ossendza, R.A., Okouo, M., et al. (1999) Les cancers primitifs du foie au Congo: Étude hospitalière de 558 cas. Médecine d Afrique Noire, 46, 394-397.

[5] Kew, M.C. (2013) Epidemiology of Hepatocellular Carcinoma in Sub-Saharan Africa. Annals of Hepatoloogy, 12, 173-182. https://doi.org/10.1016/S1665-2681(19)31354-7

[6] Camengo Police, S.M., Koffi, B., Boua-Akelelo, N.P., et al. (2014) Les complications de la cirrhose à l'hôpital universitaire de l'Amitié de Bangui. Médecine d Afrique Noire, 61, 537-542.

[7] Fares, N. and Péron, J.M. (2013) Epidemiology, Natural History, and Risk Factors of Hepatocellular Carcinoma. La Revue du Praticien, 63, 216-217, 220-222.

[8] Yang, J.D., Mohamed, E.A., Abdel Aziz, A.O., et al. (2017) Characteristics, Management, and Outcomes of Patients with Hepatocellular Carcinoma in Africa: A Multicountry Observational Study from the Africa Liver Cancer Consortium. The Lancet Gastroenterology and Hepatology, 2, 103-111. https://doi.org/10.1016/S2468-1253(16)30161-3

[9] Pugh, R.N.H., Murray-Lyon, I.M. and Dawson, J.L. (1973) Transection of the Esophagus for Bleeding Esophageal Varices. British Journal Surgical, 60, 646-654. https://doi.org/10.1002/bjs.1800600817

[10] Okud, K., Ohtsuki, T., Obata, H., et al. (1985) Natural History of Hepatocellular Carcinoma and Prognosis in Relation to Treatment. Cancer, 56, 918-928. https://doi.org/10.1002/1097-0142(19850815)56:4<918::AID-CNCR2820560437>3.0 .CO;2-E

[11] Talwalkar, J.A. and Gores, G.J. (2004) Diagnosis and Staging of Hepatocellular Carcinoma. Gastroenterology, 127, S126-S132. https://doi.org/10.1053/j.gastro.2004.09.026

[12] Luwawu, M.L. (2012) Le cancer du foie à Bukavu: Aspects épidémiologique et clinique à propos de 106 cas. Médecine d Afrique Noire, 55, 345-357.

[13] Bouglouga, O., Bagny, A., Lawson-Ananissoh, L.M., et al. (2012) Is the Management of Hepatocellular Carcinoma Evolving in Sub Saharan Africa? La Revue Médicale de Madagascar, 2, 176.

[14] Ntagirabiri, R., Munezero, B., Kaze, H., et al. (2015) Incidence du carcinome hépatocellulaire lors de l'infection chronique par le virus de l'hépatite $\mathrm{B}$. The Pan African Medical Journal, 20, 167. https://doi.org/10.11604/pamj.2015.20.167.6227 
[15] Echejoh, G.O., Tanko, M.N., Manasseh, A.N., et al. (2008) Hepatocellularcarcinoma in Jos, Nigeria. Nigerian Journal of Medicine, 17, 211-214. https://doi.org/10.4314/njm.v17i2.37386

[16] Noah, D., Andoulo, A.F., Bonny, A., et al. (2016) Prevalence of Hepatocellular Carcinoma in Carriers of Chronic Liver Disease in Yaounde-Cameroun. Revue de Médecine et de Pharmacie, 6, 507-513.

[17] Harir, N., Zeggai, S., Tou, A., et al. (2016) Hepatocellular Carcinoma in Western Algeria: Epidemiological and Clinicopathological Profile. La Revue Médicale de Madagascar, 6, 681-685.

[18] Békond, C., Mobima, T., Ouavènè, J.O., et al. (2010) Etiopathological Factors of Hepatollular Carconoma in Bangui, Central African Republic: Clinical, Biological, Characteristic and Virological Aspects of Patient. Pathologie Biologie, 58, 152-155. https://doi.org/10.1016/j.patbio.2009.07.027

[19] Borie, F., Trétarre, B., Bouvier, A.M., et al. (2009) Primitive Liver Cancers: Epidemiology and Geographical Study in France. European Journal of Gastroenterology \& Hepatology, 21, 984-989. https://doi.org/10.1097/MEG.0b013e3283293783

[20] Lambert, R. (2009) Epidemiology of Hepatocellular Carcinoma in the World. Cancérologie Digestive, 1, 86-90. https://doi.org/10.4267/2042/28030

[21] Even, C., Laumoy, G., Collet, T., et al. (1997) Epidémiologie du carcinome hépatocellulaire dans le département de calvados. Gastroentérologie Clinique et Biologique, 21, 450-458.

[22] Takayoshi, T., Yasuo, E., Nobu, H., et al. (1990) Primary Liver Cancer in Japan Clinicopathologic Features and Results of Surgical Treatment. Annales of Surgical, 211, 277-287. 